\title{
1. Spheres of influence: unpacking gender differences in negotiation
}

\author{
Mara Olekalns and Jessica A. Kennedy
}

As successive waves of research show, the role that gender plays in shaping negotiators' behaviors and outcomes is complex. Much of the initial research exploring gender differences was built around the simple and intuitive proposition that women are (and are expected to be) more cooperative than men. This intuition is not wholly unfounded. Two seminal meta-analyses confirmed that women are more cooperative, and obtain lower outcomes, than men when they negotiate (Stuhlmacher and Walters, 1999; Walters et al., 1998), and that they are less likely than men to initiate negotiations (Kugler et al., 2018). Complementing these quantitative meta-analyses, a qualitative review concluded that women are more egalitarian than men, expecting and asking for less and more readily reaching agreement (Eckel et al., 2008). Paralleling the economic losses that women garner when they negotiate, a steady stream of research shows that they also incur social costs: women who ask are perceived as more pushy and unlikeable and as undesirable team members (Bowles et al., 2005; 2007).

Explanations for these differences draw on two related constructs: relational self-construal and role congruity. Women's greater cooperativeness is often attributed to the emphasis that they place on preserving relationships: their interdependent self-construal translates into greater communality and other-concern (Gelfand et al., 2006; Gray, 1994). In negotiations, this manifests as reluctance to disrupt relationships by asking at all, by asking for 'too much', or by pushing for better offers. The expectation that women are more other-oriented also invites exploitation: women are offered less, are expected to accept less, and are less likely than men to be treated fairly (Fabre et al., 2016). The belief that women are more other-oriented than men is complemented by the behavioral expectations that social roles generate (Stuhlmacher and Linnabery, 2013). These behavioral expectations both describe what women (and men) do and prescribe what they should do. The social costs incurred by female negotiators are attributed to the violation of prescriptive stereotypes (Kulik and Olekalns, 2012; Kray and Thompson, 2005); when women advocate for themselves, they violate expectations that they will display warmth and other-concern.

Understanding how gendered expectations shape women's economic and social outcomes is the beginning of our story rather than its end. Driven by factors such as the gender wage gap, much of the early research focused on how gender differences influence the outcome of compensation negotiations. While this research has given us substantial and important insights into salary negotiations, the depth of our understanding comes at the expense of breadth. It is worth asking whether the gender 
disadvantage persists when women negotiate outside of their work environment or when they negotiate about non-economic issues. Recent meta-analyses suggest that the gender disadvantage observed in salary negotiations does not necessarily persist in other contexts. Mazei et al. (2015) report that gender differences are reduced when negotiators are experienced, when the bargaining range is known, and when individuals are negotiating on behalf of others. Context can amplify or attenuate the social cost of negotiating (Eckel et al., 2008) and even reverse the disadvantage when it reduces role incongruity (also, Kugler et al., 2018).

In their chapters, our authors give us an ever broader and more nuanced understanding of how gender affects negotiations. We have organized the chapters into parts that move from more proximal to more distal influences on negotiation. Following this introduction, Part II of this book stays close to individual negotiators and is organized around the theme of relationships. Broadening our perspective a little, the third part of this book considers how the behavioral context - specifically the gender of female negotiators' partners - impacts their experience of negotiation. One step further out, the fourth part of this book considers how some of the core aspects of negotiation - trust, power, communication - and the intersection of race and gender add nuance to the negotiation process. In Part V, we turn to the critical issue of how women can build self-efficacy and the resilience to overcome setbacks in their negotiations. Finally, we conclude in Part VI.

\section{PART II - FRIENDS, FAMILIES, WORK: NEGOTIATING IN LONG-TERM RELATIONSHIPS}

Although research has emphasized the negotiation of wages and other tangible resources, these negotiations represent a small fraction of our everyday negotiations. Even when researchers consider the relationship between negotiators, they typically remain focused on economic outcomes. Not only does this emphasis on economic outcomes offer a narrow view of the kinds of negotiations that characterize our lives, it also offers a narrow view of the kinds of relationships within which negotiations take place. While informative, the pervasive focus on short-term, transactional negotiations does not deepen our understanding of how individuals in close and long-term relationships navigate the inevitable bumps that punctuate such relationships.

It is arguable that many more of our negotiations take place in the context of close or ongoing relationships. How does this context change the way that negotiations are conducted? Finkel et al.'s (2017) synthesis of the close relationship literature suggests several critical features of close relationships that are pertinent to negotiations. Interdependence increases because boundaries between individuals are less distinct than in more distant relationships, and the long-term trajectory of close relationships means that they are characterized by greater intimacy and commitment. This sense of commitment provides a platform that enables partners to persevere in their relationships. More broadly, the close relationships literature shifts focus from economic 
to social capital, reminding us that factors such as fairness, trust, and liking are more important than substantive outcomes in many relationships.

The first two chapters in this section sit at the intersection of the negotiation and close relationships literatures, drawing attention to the importance of maintaining and building social capital in negotiations. Within this context, Gallagher, Burns and Stuhlmacher explore the dynamics of one aspect of close relationships: friendship maintenance. These authors highlight the central role of reciprocal exchange in relationship maintenance, exploring how gender affects the importance of social outcomes and the perception of reciprocity violations. Livingston and Ryu explore a different aspect of relationship maintenance, that of role expectations, in their chapter. Focusing on spousal negotiations, they draw attention to the implicit negotiation and renegotiation of household roles and the possible resolution of role conflict that lies beneath negotiation of substantive issues. They propose that the extent to which this subtext is a critical force in spousal negotiation may be the result of how strongly spouses endorse traditional role expectations.

Spousal and workplace negotiations are united by efforts to negotiate boundaries, specifically to create balance between work and home. There is ample evidence that the intrusion of work on family life, or vice versa, creates tension, reduces the amount of time spent on relationship-building activities, and depletes coping resources (Finkel et al., 2017; Karney and Neff, 2013). Negotiating work-family arrangements is thus critical to preserving relationships in both spheres. Addressing this issue, Bear and Pittinsky discuss gender differences in the context of career advancement gaps and work-family arrangements. These authors propose that 'caregiving ambition' is a more critical determinant of willingness to negotiate work-family arrangements than gender and further propose that the precise form of these arrangements will be determined by the degree of both career and caregiving ambition. In the last chapter of this section, Bochantin and Dickson focus on the micro-negotiations that underpin women's management of work and family within a unique context, that of first responders. This chapter highlights the challenges, especially for women, in pursuing both career and caregiving goals and builds our understanding of how women 'bend' (Bowles et al., 2019) their workplaces to support caregiving goals.

\section{PART III - BOUNDED NEGOTIATIONS: GENDERED NORMS AS CONSTRAINTS}

Our relationships, and consequently our negotiations, are embedded with social context. We, and several of our authors, have touched on the role played by normative expectations in shaping how women are expected to behave and how their actual behaviors are judged. The Stereotype Content Model, which sets out normative expectations and the consequence of violating those expectations, continues to be a dominant model in this field. According to the Stereotype Content Model, women are expected to display warmth and other-concern and when they violate these norms, they experience backlash (Fiske et al., 2002). As many negotiation research- 
ers have subsequently shown, when women violate norms by self-advocating, they incur social costs (Kray and Thompson, 2005; Kulik and Olekalns, 2012). More recent research, however, highlights that these norms establish expectations not just about how women should behave but how they are expected to react to others' behavior. Focusing specifically on deception, Jazaieri and Kray highlight the ways that normative expectations shape ethical behavior in negotiations: although women are less likely to engage in unethical behaviors, they are judged more harshly when they do; and, consistent with the expectation that women prioritize relationships, women elicit more deception than men in their negotiations. These authors also draw attention to gender differences in negotiators' underlying motives: whereas men are more likely than women to use self-serving deceptive tactics, women are more likely than men to use other-serving deceptive tactics.

Jazaieri and Kray's chapter highlights the different ethical standards that women and men apply and elicit, hinting at the possibility that standards are relative rather than absolute. The idea of shifting standards has been elaborated by Biernat and colleagues (e.g., Biernat and Vescio, 2002). Broadly, the shifting standards model proposes that judgments about behaviors are made relative to the social group within which they occur. An implication of this model is that the characteristics of the individual negotiator do not wholly capture likely behaviors at the negotiating table. Rather, we need to know about the dyad's characteristics. Demonstrating this point, behavioral economists have shown that men cooperate less when observed by other men whereas women cooperate more when observed by other women (Charness and Rustichini, 2011). In negotiations, strategy choices differ depending on whether negotiators have the same or different goals, the same or different levels of power, or are negotiating in same or mixed-sex dyads (e.g., Olekalns and Smith, 2003; Olekalns et al., 2014). Two chapters develop this point. Kesebir, Lee, Qiu and Pillutla discuss the development of behavioral norms in same-sex groups and extend these developmental differences to negotiations. Drawing on interactions between same-sex peers, these authors propose that men may be more effective in multi-party negotiations, more willing to shift alliances to gain an advantage, and better able to claim value. In contrast, women are likely to avoid strategies that escalate tension and consequently will be less assertive in negotiations with other women than with men. Drawing on role congruity theory, Stuhlmacher and Zervos refine our understanding of how dyad composition shapes negotiations. They draw on two theoretical perspectives - role congruity and authenticity (the SAFE model) - to highlight the role that context and framing play in determining when gender roles gain prominence in negotiations. Individuals hold multiple roles, and these roles can increase or decrease in salience as negotiations unfold. Stuhlmacher and Zervos draw attention to the possibility that gender roles are more salient - and expectations of gender congruent behavior more pronounced - in mixed-sex dyads. Those authors extend our understanding of context by highlighting how context, including others' reactions, shapes women's feelings of authenticity. Together, these two perspectives help us to understand when and why gender stereotypes play a role in female negotiators' outcomes. 
It is possible to broaden the consideration of normative influences even further. As Finkel et al. (2017) note, relationships are embedded within social networks and also within a broader cultural context. Thus, norms and their influence on negotiations are likely to shift as the broader social and cultural context changes. Taking a broad historical perspective, Elias addresses this topic, analyzing how - over time - women have been able to use their legitimate power to shape and influence their circumstances.

\section{PART IV - BEHIND-THE-SCENES: GENDER DIFFERENCES IN UNDERLYING PROCESSES}

Social context exerts a powerful, if unseen, influence both on how negotiations develop and how they end. The social context colors and shapes not only what individuals do but also how others interpret their actions. High-quality relationships are a critical part of social context, underpinning individuals' willingness to act collaboratively. Trust (and trust violations) reside at the very heart of such relationships. Several meta-analyses show that both individual and dyadic trust shape negotiators' strategy choices and their ability to create value (Kong et al., 2014; Korsgaard et al., 2015). Given the extensive attention that trust has received, it is perhaps surprising that negotiation researchers have as yet given little attention to whether both trust and trustworthiness are shaped by gender. Other literature, however, hints at a relationship between gender and trust. For example, Wu et al. (2018) show that, in ultimatum games, facial trustworthiness is more important when proposers are men than when they are women. In his chapter, Haselhuhn draws on several related literatures including behavioral economics and leadership to tease out the ways that gender might influence perceptions of trustworthiness in negotiation. Overall, research suggests that men are more trusting than women, and that women are more trusted than men. However, as Haselhuhn points out, these differences fade as the social situation becomes more nuanced, and the extent to which these differences influence negotiation behavior is as yet unclear.

Power relationships are a second defining feature of social context and a pervasive influence on negotiations. How negotiators build power and influence their opponents is one of the most enduring questions of negotiation research. Much of this research has centered on the concept of alternatives, the idea that power increases as the range of available alternatives increases. Although this research has predominantly focused on personal power, there is recognition that the distribution of power between individuals is critical to how it impacts negotiation. Like research on trust, research on power in negotiations has paid relatively little attention to the subtler influence that gender might have on how power is built, used, and responded to in negotiations.

A recent meta-analysis, however, identifies suggestive links between influence and gender: men are more likely to use male-stereotyped (agentic) influence tactics, and women are more likely to benefit from using female-stereotyped (communal) 
influence tactics (Smith et al., 2013). This theme is taken up by Trombini and her co-authors in their chapter in power and affect in negotiation. Focusing on contexts that prime a male gender stereotype, Trombini et al. propose that, especially in negotiations with men, the expression of either anger or anxiety will harm women's social and economic outcomes. Intriguingly, they also propose that women will achieve poorer social and economic outcomes if their male counterparts experience either anger or anxiety.

Integrating theories of trust and power, Wareham and Overbeck focus on how gender shapes the use and interpretation of nonverbal communication. They draw together several constructs - power, communication, and mixed-gender dyads - to elucidate how negotiators' gender might influence the use and interpretation of nonverbal communication. Nonverbal cues can signal both dominance and affiliation, and their use can be either congruent or incongruent with gender stereotypes. Wareham and Overbeck argue that, in mixed-gender dyads, female negotiators will be disadvantaged when nonverbal cues are incongruent with gender stereotypes and may especially benefit from the strategic use of gender-congruent nonverbal cues. Taking a broader perspective on communication processes, Liu and Ren highlight key differences in the ways that men and women communicate. Focusing on nonverbal cues, they discuss the greater tendency of men to engage in dominance displays. Turning to verbal cues, they highlight the greater willingness of partners to interrupt women, and also highlight women's greater use of accommodation, a convergence to others' speech styles that signals affiliation.

This section finishes with a discussion of how culture, race, and gender might intersect to influence negotiation. Toosi and her co-authors show that the familiar backlash effect in which women incur social costs for negotiating is apparent only in individualistic (Western) cultures. Their review suggests that women incur backlash when they violate gender stereotypes, but that these stereotypes are culturally influenced.

\section{PART V - STRONGER SELF-ADVOCATES: PERSISTING DESPITE DISRUPTIONS AND SETBACKS}

Although 'normal' adversities such as threats, ultimatums and unexpected changes in strategy are commonplace in negotiations (Neville et al., forthcoming), relatively little is known about how these setbacks can be overcome (Spector, 2006). What the literature does clearly convey, however, is that how negotiators respond in the moments immediately following setbacks is critical to the success of negotiations. The extensive literature on turning points demonstrates that, when negotiators encounter such events, their actions can either re-establish progress towards agreement or escalate tensions and move negotiations away from agreement (Druckman and Olekalns, 2013). Similarly, Weingart et al. (2015) propose that how conflicts develop depends not on the nature or intensity of the conflict but on what disputants do next. This topic is critical for women because of their suspected propensity to end 
negotiations when they encounter setbacks (Babcock and Laschever, 2003) and their exceptional potential to re-establish cooperation and repair the relationship (Kennedy and Kray, 2015). The impact of what negotiators do next is at the heart of the first chapter in this part. Kolb and her co-authors not only talk about how to use 'turns' to overcome these points of adversity within the context of political negotiations, they also give us insight into points of resistance that trainers might encounter as they introduce new ideas. Drawing on their own experiences, the authors consider how these moments can be 'turned' to enhance participants' learning and skill development.

The discussion of turns places emphasis on other-management - that is, on changing the behaviors of an opponent in order to transform the negotiation dynamic. But negotiators also need to self-manage - that is, to build a robust platform from which to launch their negotiations. To better self-manage, negotiators need become effective perspective-takers and emotion managers. Perspective-taking is critical to how negotiators interpret their counterparts' actions, especially those that disrupt a negotiation. It helps them to lay the foundation for a more constructive response to disruptions. Alongside perspective-taking, negotiators need to manage their own and others' emotions effectively. Perspective-taking provides an important tool for doing so: if negotiators can acknowledge others' or their own emotions, they are better able to understand and address the underlying triggers for those emotions. Much of the focus on emotion centers on anxiety and anger and the role of perspective-taking in effectively responding to those emotions. This is important because both emotions can disrupt negotiations, anxiety because it affects negotiators' willingness to initiate negotiations (Brooks and Schweitzer, 2011) and anger because it spreads from one negotiator to the other, inflaming the situation (Olekalns and Rees, in press).Women, who report greater anxiety about negotiation than men, will become stronger self-advocates if they can harness the power of anxiety to motivate better preparation for negotiations (Brooks, 2014).

Kulik, Sinha and Olekalns' chapter describes six self-management challenges identified by the women they interviewed. Some of these challenges reflect the core negotiation tasks of better planning, better goal-setting, and understanding their value. There was also an implicit recognition of gender bias, especially the need to balance self-advocacy against communality. Beyond this, the women in this study recognized the need to better manage the negotiation process. They identified important challenges beyond the basics: overcoming pre-negotiation nerves, managing emotions in-the-moment, and being persistent. This chapter, in identifying perspective-taking and emotion management as two skills that are critical to enhancing women's ability to self-advocate, touches on the idea of resilience. The overarching theme of resilience, which underlies the discussion of turns and women's self-advocacy, is addressed more directly in the final chapter.

Gazdag integrates the resilience and negotiation literatures to identify the factors that influence women's ability to 'bounce back' from adverse experiences in negotiation. In doing so, Gazdag provides depth to some of the challenges identified in Kulik and co-authors' interviews. Drawing from negotiation and resilience literatures 
suggests that, before negotiating, women will benefit not only from building their self-efficacy, but also that self-reflection can help them to identify and address weak spots, and coaching can help them to overcome psychological barriers. A common theme through all three chapters was the need to anticipate sticking points ahead of time, to identify constructive responses and to build them into a flexible behavioral repertoire. Finally, Gazdag suggests that women are well-placed to be highly effective negotiators because they are more likely than men to approach negotiations with a process mindset and willingness to engage in perspective-taking and problem-solving.

\section{IN CONCLUSION: THREADS RUNNING THROUGH}

We organized our chapters based on the immediacy of influence exerted by gender. This influence is clearest when we consider interpersonal relationships, becomes subtler when we consider the context within which negotiations take place, and becomes even more subtle as we focus on how gender might shape more fundamental interpersonal processes. As we reviewed our chapters, we identified three threads running through these spheres of influence: social capital, social context, and social processes.

\section{Social Capital}

In recent years, research has pivoted from focusing on the role gender plays in shaping economic outcomes to the role gender plays in determining social outcomes such as likeability, trustworthiness, and reputation. This shift in focus started with the finding that women who initiate negotiations are likely to incur social costs: they are perceived as less likeable and as less desirable team members. These findings parallel a broader literature on backlash effects that establishes the social costs women incur when they violate gender-based expectations (the second thread, below). The importance of social capital has been further highlighted by Curhan and colleagues' research (Curhan et al., 2009), which shows that the social capital that negotiators accumulate in one negotiation spills over to influence economic outcomes in subsequent negotiations.

Social capital threads through the first three parts of this book. Across these parts, we learn that women may start with higher social capital in the form of higher trustworthiness; they may be considered more benevolent and as having greater integrity than men (Haselhuhn, Chapter 10). These expectations may, however, backfire if women then fail to signal these qualities. Jazaieri and Kray (Chapter 6) hint at this possibility in their discussion of ethics. Negotiators, generally, risk loss of social capital when they engage in deception but research shows that - because women are expected to be more ethical - the tolerance for their ethical transgressions is lower than for men. Approaching this issue from a slightly different angle, Gallagher et al. (Chapter 2) focus on the accumulation of social capital within friendships and the 
possibility of using that social capital for personal gain. The idea that women can accumulate social capital for instrumental purposes adds an interesting twist to our story because of the potential repercussions that women - but not men - encounter when their relationship behaviors are perceived to be inauthentic. A further twist is added by Toosi and co-authors (Chapter 14), who propose that backlash for assertiveness may be mitigated in collectivist cultures.

We thus see that women's negotiation behaviors are evaluated against societal expectations of how they should behave, and violating these expectations incurs social costs. Our authors hint at two underexplored factors beyond the stereotype-based expectations that more typically guide our analyses of backlash effects. These factors have the potential to shape when backlash is elicited. The first is the relationship history within which a violation takes place. Trust research implies that how women accrue and erode trust needs to be assessed against the nature and depth of their relationships. The second is the efficacy of mitigation strategies. Our authors touch on the importance of explanations and apologies in mitigating expectancy violations, suggesting the need to understand whether the mechanisms of mitigation differ for women and men.

\section{Social Context}

Because social capital is assessed against our expectations of women, it is closely intertwined with social context. Societal expectations of women's behavior set one dimension of social context. Our authors highlight three models that give insight into this dimension: stereotype content, role congruity, and shifting standards. Importantly, they also draw attention to broader contextual factors to add nuance to our understanding of when these expectations are more or less salient in others' reactions to women.

The first strand of the social context thread identifies the influence of broad societal and contextual norms in shaping when and how women negotiate, as well as the consequences when they do initiate negotiations. At the very broadest level, social and gender norms influence gender role salience. Because we all hold multiple roles, it is important to understand the circumstances in which the salience of gender roles dominates the salience of other roles we might hold. As Trombini et al. highlight in their chapter (Chapter 11), this influence can be subtle: they describe 'male stereotype dominated' environments in which the link between male-stereotyped behaviors and effective negotiation is reinforced, according men an advantage in negotiation. Small-scale versions of this context are triggered when negotiations occur between men and women, either by chance or because they occur in relationships that assign differential roles (and power) to partners. The context increases the accessibility and salience of gender roles either because it is a visible point of difference (for example in mixed-gender dyads; Stuhlmacher and Zervos, Chapter 8) or because social norms increase the salience of gender roles (Livingston and Ryu, Chapter 3). When gender roles are not salient, as is the case within all-female groups, the context primes 
a negotiation style that emphasizes loyalty and the preservation of relationships, which brings with it a different set of challenges (Kesebir et al., Chapter 7).

Gender-based expectations also shape the nuance of social interactions. The second strand of the social context thread suggests that how negotiators communicate and build relationships is shaped by who they negotiate with. Individuals adjust their nonverbal, paraverbal and verbal behaviors based on the context within which they negotiate. Across all three levels of communication, when women and men interact - a context that increases the salience of gender stereotypes - men's communicative behavior reflects dominance and nonaffiliation whereas women's communicative behavior reflects submissiveness and affiliation (Wareham and Overbeck, Chapter 12; Liu and Ren, Chapter 13). These patterns reflect the different expectations of women and men and raise the interesting question of what happens when women's communication styles violate gender-based expectations. In contexts such as those we described above, the increased salience of gender roles suggests that women who display dominance either through their nonverbal actions or through verbal behaviors (such as influence attempts) may trigger backlash, including whether women are perceived as trustworthy.

\section{Social Processes}

Social exchange theory provides a different perspective on the idea of expectations. Briefly, this theory proposes that our social relationships are built on the exchange of both tangible and intangible goods. We give goods to initiate relationships and maintain them by reciprocating when others give us goods. As Gallagher and co-authors (Chapter 2) remind us, the norms of reciprocity are shaped by the nature of our relationships with others. Not only does the nature of reciprocity (economic versus social) evolve as we move from short- to long-term relationships, but so too does our tolerance for violations of the norm. These factors may also vary depending on whether the friendships are with other women or with men.

Two chapters encourage us to step back and consider how these broader societal norms might shape women's negotiations. Focusing on the negotiation of work-family issues, Bear and Pittinsky (Chapter 4) argue that it may be the balance between care-giving and career ambitions that determine when and what men and women negotiate. In short, they propose an alternative set of norms that shape the behavior of women and men at the negotiating table. Turning to a more distinctive negotiation context, Bochantin and Dickson (Chapter 5) focus on how male and female first responders negotiate work-life balance. They draw attention to the greater difficulties in negotiating work-life issues in this male-dominated context, highlighting the need for women to suppress or conceal caregiving ambitions in order to pursue a successful career. They describe several strategies used by women to 'bend' their organizational norms and their working lives to meet their care-giving responsibilities. Stepping back, the authors emphasize that the solution is to develop norms that recognize care-giving needs as an organizational rather than a personal issue. To this end, the final chapters on managing and overcoming resistance give us 
ideas for how women can micro-manage their workplace negotiations to overcome resistance, moving forward from a position of confidence and strength (Kolb et al., Chapter 15; Kulik et al., Chapter 16; Gazdag, Chapter 17).

\section{REFERENCES}

Babcock, B., and Laschever, S. (2003). Women don't ask: Negotiation and the gender divide. Princeton, NJ: Princeton University Press.

Biernat, M. and Vescio, T.K. (2002). She swings, she hits, she's great, she's benched: Implications of gender-based shifting standards for judgment and behavior. Personality and Social Psychology Bulletin, 28, 66-77.

Bowles, H.R., Babcock, L. and Lai, L. (2007). Social incentives for gender differences in the propensity to initiate negotiations: Sometimes it does hurt to ask. Organizational Behavior and Human Decision Processes, 103, 84-103.

Bowles, H.R., Babcock, L. and McGinn, K.L. (2005). Constraints and triggers: Situational mechanics of gender in negotiation. Journal of Personality and Social Psychology, 89, 951-65.

Bowles, H.R., Thomason, B.J. and Bear, J.B. (2019). Reconceptualizing what and how women negotiate for career advancement. Academy of Management Journal, 62(6).

Brooks, A.W. (2014). Get excited: Reappraising pre-performance anxiety as excitement. Journal of Experimental Psychology: General, 143, 1144-58.

Brooks, A.W. and Schweitzer, M.E. (2011). Can Nervous Nelly negotiate? How anxiety causes negotiators to make low first offers, exit early, and earn less profit. Organizational Behavior and Human Decision Processes, 115, 43-54.

Charness, G. and Rustichini, A. (2011). Gender differences in cooperation with group membership. Games and Economic Behavior, 72, 77-85.

Curhan, J., Elfgenbein, H.A. and Kilduff, G.J. (2009). Getting off on the right foot: Subjective value versus objective value in predicting longitudinal job outcomes from job offer negotiations. Journal of Applied Psychology, 94, 524-34.

Druckman, D. and Olekalns, M. (2013). Punctuated negotiations: Transitions, interruptions and turning points in negotiation. In M. Olekalns and W. Adair (eds), Handbook of Research on Negotiation. Cheltenham, UK and Northampton, MA, USA: Edward Elgar Publishing.

Eckel, C., de Oliveira, A. and Grossman, P. (2008). Gender and negotiation in the small: Are women (perceived to be) more cooperative than men? Negotiation Journal, 24, 429-55.

Fabre, E.F., Causse, M., Pesciarelli, F. and Cacciari, C. (2016). The responders' gender stereotypes modulate the strategic decision-making of proposers playing the ultimatum game. Frontiers in Psychology, 25 January, ArtID 12.

Finkel, E., Simpson, J. and Eastwick, P. (2017). The psychology of close relationships: Fourteen core principles. Annual Review of Psychology, 68, 383-411.

Fiske, S.T., Cuddy, A.J.C., Glick, P. and Xu, J. (2002). A model of (often mixed) stereotype content: Competence and warmth respectively follow from perceived status and competition. Journal of Personality and Social Psychology, 82, 878-902.

Gelfand, M.J., Major, V., Raver, J.L., Nishii, L.H. and O’Brien, K. (2006). Negotiating relationally: The dynamics of relational self in negotiations. Academy of Management Review, 31, 427-51.

Gray, B. (1994). The gender-based foundations of negotiation theory. Research on Negotiation in Organizations, 4, 3-36.

Karney, B.R. and Neff, L.A. (2013). Couples and stress: How demands outside a relationship affect intimacy within the relationship. In J.A. Simpson and L. Campbell (eds), The Oxford Handbook of Close Relationships (pp. 664-84). New York: Oxford University Press. 
Kennedy, J.A. and Kray, L.J. (2015). A pawn in someone else's game? The cognitive, motivational, and paradigmatic barriers to women's excelling in negotiation. Research in Organizational Behavior, 35, 3-28.

Kong, D.T., Dirks, K.T. and Ferrin, D.L. (2014). Interpersonal trust within negotiations: Meta-analytic evidence, critical contingencies, and directions for future research. Academy of Management Journal, 57, 1235-55.

Korsgaard, M.A., Brower, H.H. and Lester, S.W. (2015). It isn't always mutual: A critical review of dyadic trust. Journal of Management, 41, 47-70.

Kray, L.J. and Thompson, L. (2005). Gender and negotiation. Research in Organizational Behavior, 26, 102-82.

Kugler, K.G., Reif, J.A.M., Kaschner, T. and Brodbeck, F.C. (2018). Gender differences in the initiation of negotiations: A meta-analysis. Psychological Bulletin, 144, 198-222.

Kulik, C. and Olekalns, M. (2012). Negotiating the gender divide: Lessons from the negotiation and organizational behavior literatures. Journal of Management, 38, 1387-415.

Mazei, J., Huffmeier, J., Freund, P.A., Stuhlmacher, A.F., Bilke, L. and Hertel, G. (2015). A meta-analysis on gender differences in negotiation outcomes and their moderators. Psychological Bulletin, 141, 85-104.

Neville, L., Caza, B.B. and Olekalns, M. (forthcoming). Negotiation resilience: A framework for understanding how dyads learn and grow from negotiation adversity. In N. Powley, B.B. Caza and A. Caza (eds), Research Handbook on Organizational Resilience, Cheltenham, UK and Northampton, MA, USA: Edward Elgar Publishing.

Olekalns, M., and Rees, L. (forthcoming). Emotion in negotiation. In R. Cropanzano, V. Martines-Tur, C. Daus and L-Q. Yang (eds), The Handbook of Workplace Affect. Cambridge: Cambridge University Press.

Olekalns, M. and Smith, P.L (2003). Social motives in negotiation: The relationship between dyad composition, negotiation processes and outcomes. International Journal of Conflict Management, 14(3-4), 233-54.

Olekalns, M., Kulik, C. and Chew, L. (2014). Sweet little lies: Social context and the use of deception in negotiation. Journal of Business Ethics, 120, 13-26.

Smith, A.N., Watkins, M.B., Burke, M.J., Christian, M.S., Smith, C.E., Hall, A. and Simms, S. (2013). Gendered influence: A gender role perspective on the use and effectiveness of influence tactics. Journal of Management, 39, 1156-83.

Spector, B.I. (2006). Resiliency in negotiation: Bouncing back from impasse. International Negotiation, 11, 273-86.

Stuhlmacher, A.F. and Linnabery, E. (2013). Gender and negotiation: A social role analysis. In M. Olekalns and W.L. Adair (eds), Handbook of research on negotiation research (pp. 221-48). Cheltenham, UK and Northampton, MA, USA: Edward Elgar Publishing.

Stuhlmacher, A.F. and Walters, A.E. (1999). Gender differences in negotiation outcome: A meta-analysis. Personnel Psychology, 52, 653-77.

Walters, A.E., Stuhlmacher, A.F. and Meyer, L.L. (1998). Gender and negotiator competitiveness: A meta-analysis. Organizational Behavior and Human Decision Processes, 76, 1-29.

Weingart, L.R., Behfar, K., Bendersky, C., Todorova, G. and Jehn, K. (2015). The directions and oppositional intensity of conflict expressions. Academy of Management Review, 40, 235-62.

Wu, Y., Gao, L., Wan, Y., Wang, F., Xu, S., Yang, Z., Rao, H. and Pan, Y. (2018). Effects of facial trustworthiness and gender on decision making in the Ultimatum Game. Social Behavior and Personality: An International Journal, 46, 499-516. 